\title{
Diagnosis of varicose veins of the lower limbs - functional tests
}

\author{
Agnieszka Pedrycz $_{\text {ABCDEFG }}$, Beata Budzyńska ${ }_{\text {ABCDEFG }}$ \\ Departament of Histology and Embryology, Medical University in Lublin, Poland
}

\begin{abstract}
Varicose veins of the lower limbs are dilated, gnarled, swirled and twisted superficial veins with balloon -like bulges. They are divided into two types - primary varicose veins with normal deep veins and secondary ones which develop after trauma or superficial phlebitis. They form in various locations, e.g. on the great saphenous vein, accessory posterior and anterior saphenous vein and small saphenous vein. Present study presents functional tests used in diagnosis of variose veins.
\end{abstract}

Key words: varicose veins, functional tests

\section{Symptoms and causes}

Primary varicose veins are caused by a decrease of the elastic tissue amount in venous walls, which become less stretching-resistant. The dilation of venous walls leads to valve failure resulting in backward flow and accumulation of larger amounts of blood and contributes to further dilation of vessels. [1].

Secondary varicose veins are caused by increased volumes of blood flowing through superficial veins of lower limbs due to obstructed deep veins. In many cases, an increased blood flow may result from valve malfunction in the perforator and deep veins $[2,3,4]$.

At the initial stage, varicose veins do not always cause pain. The main reason why patients seek medical attention at this point is a cosmetic defect. The first symptom is a discomfort - tiredness and heaviness of legs, night cramps. The subsequent symptoms include swelling of the lateral and medial ankle as well as the dorsum of the foot, dull or burning pain, paraesthesia. The changes visible on the lower limbs include spider veins or wiggly -shaped small swellings under the skin surface. The swellings are soft and painless and their sizes depend on the limb position. On palpation, the great saphenous vein is an elastic strained robe, often enlarging on coughing. Moreover, the skin in the ankle area may undergo the following changes: discolourations, hardenings, eczema and swellings in the shin area which may persist even after a night rest [5].

Varicose veins in pregnant women cause more symptoms than those in non-pregnant individuals $[4,6]$.

One of the main causes of the development of varicose veins is malfunctioning or complete ab- sence of valves in the superficial veins. When a valve is not present or cannot close completely, the blood carried to the heart flows partly backward. It accumulates in the veins and increased pressure stretches the veins leading to the development of varices [7].

Malfunctioning of vein valves is often a genetic defect. The risk of varicose veins in children of the affected parents is $90 \%$. If varices are present only in one of the parents, the risk is $60 \%$ in females and $25 \%$ in males. Varicose veins are extremely rare in children whereas their incidence in 60-year-olds individuals is sixfold higher, compared to 30 -year-olds.

In the standing position, the distance the blood has to travel to reach the heart is prolonged. When the legs do not move, the muscle pump stops and the immobilized calf muscles do not push blood towards the heart [8]. In the sitting position, the legs do not move and are bent in the hip and knee joints; therefore, the blood flow towards the heart is more difficult resulting in muscle pump malfunction.

Individuals with the recommended body weight increased by $20 \%$ are susceptible to venous insufficiency. Excessive weight overburdens the legs, which hinders movements and provokes the sedentary lifestyle. Consequently, the venous blood flow is impaired. Obesity increases the risk of varices, especially in female patients [9].

Hormonal changes during pregnancy and the accompanying circulatory strain cause venous insufficiency of the lower limbs.

The other factors that may contribute to the development of varicose veins include oral contraceptives, hormone replacement therapy, tobacco, low-fibre diet, hot baths, sauna, solarium (high 
temperature dilates the vein, which slows the blood flow to the heart), weight lifting (increased pressure in the abdominal cavity exerts pressure on veins which impairs the blood flow to the legs).

Moreover, the way we dress affects the development of varicose veins as well. Tight underwear or uncomfortable high heel shoes, which disturb the proper heel-to-toe movement, considerably reduce the activity of calf muscles.

The performance of the lower limb muscle pump is also impaired by hindered movement of the joints caused by changes in their structure [10].

\section{Diagnosis of varicose veins}

During the first stage of diagnosis, the patient's medical history is carefully taken. Subsequently, the patient undergoes the physical examination aided with detailed diagnostic methods. Duplex and Doppler ultrasound procedures allow more accurate anatomical and functional evaluation of the deep vein system [11].

\section{Case history}

The characteristics and localization of the ailments reported by patients with venous insufficiency are often non-specific. Diagnosis requires extreme scrutiny. Questions should focus on predisposing factors, causes and symptoms of venous insufficiency.

It is crucial to analyze present health problems, the way they manifest themselves, their duration, speed of development, type of discomfort and the applied treatment.

Moreover, the time that lapsed from the first signs and the size of the affected area (both or one leg) are of importance.

The patient's lifestyle should also be analyzed, including physical activity, living environment such as temperature and climate, use of compression therapy and its effectiveness [12].

The symptom indicating venous insufficiency is difficulty with putting on shoes at the end of the day, including pain (location), swelling (time of the day, size), restless legs syndrome, night cramps, "heavy" legs.

\section{Assessment of risk factors}

- lifestyle - sports, physical activity, type of work (physical, standing, sedentary),

- genetic predispositions - varicose veins, embolism, chronic venous insufficiency, thrombosis, ulcerations,

- drugs - hormones and oral contraception,
- obstetric medical history,

- injuries - surgeries, immobilization,

- overweight, obesity,

- tobacco smoking,

- history of vein diseases (deep vein thrombosis, previous varicose veins, pulmonary embolism, lower leg ulcerations, superficial thrombophlebitis, previous antithrombotic treatment, temporary oedema of legs after an injury, immobilization after surgery or labour) $[13,14]$.

\section{Functional tests}

When the functional tests of the vascular system have become routinely applied, the venous functional tests are less commonly used. However, some of them, such as Linton, Schwartz or Tredelenburg tests are still popular since they are time- and cost-effective, providing simple and quick classification of patients. The other tests may be replaced by Doppler US or plethysmography. All these diagnostic methods enable quick assessment of the condition of deep and perforating veins.

\section{SCHWARTZ TEST (wave test, percussion symptom)}

The test reveals incompetence of valves of the superficial veins.

Procedure: the patient is in a standing position and the physician palpates the varicose vein with the fingertips of one hand and taps the varicosity or the closest vein with the fingertips of the other hand.

Interpretation: the occurrence of the shock wave confirms the venous reflex. The test can also be modified so that the doctor taps the further segment of the vein and presses the vein or the closest varicosity with the fingertips. The shock wave proves the relation between the two vein segments [14].

\section{LINTON TEST}

The test confirms occlusions in the deep vein system.

Procedure: the patient is in a standing position and a tourniquet is placed below the knee blocking superficial return of venous blood. Subsequently, the patient is quickly placed supine and elevates the leg.

Interpretation: if the blood flow in the deep vein system is not disturbed, the varices empty quickly. If, on the other hand, the system is occluded, the varices empty slowly or remain dilated [14]. 


\section{TREDELENBURG TEST}

The test evaluates varicosity of thighs. It controls the function of the small saphenous vein and perforating veins.

Procedure: the patient is placed supine with the leg elevated, the therapist looks for dilated veins, applies a tourniquet on the upper part of the thigh and allows the patient to stand up.

Interpretation: If the varices do not fill or fill slowly within half a minute after standing up but when the tourniquet is removed they fill fast within a few seconds, it means the great saphenous vein is occluded but the perforating veins are not affected. Their relatively fast filling from the proximal side may indicate small saphenous vein occlusion and from the distal side - insufficiency of perforating veins [14].

\section{PRATT TEST}

The test is used to locate the places of perforating vein insufficiency.

Procedure: the patient elevates the leg and the doctor places a tourniquet between the foot and the upper $1 / 3$ of the thigh. Elastic bandage is placed proximally and the patient stands up. The doctor applies another elastic bandage in place of the tourniquet. The lower bandage is slowly unveiled whereas the upper one is wrapped around the limb. The therapist tries to leave only a small fragment of the skin between the bandages not pressed.

Interpretation: the fragment where the skin is not pressed reveals incompetent perforating veins [14].

\section{Invasive tests}

In order to supplement the physical examination, some function-assessing tests are performed, including the following:

- Duplex - Doppler test,

- Duplex ultrasounu imaging,

- X-ray examination,

- magnetic resonance imaging (with a contrast agent),

- phlebodynanometry,

- plethysmography (during exercise and at rest),

- transcutaneous oximetry,

- thermography,

- angioscopy,

- capillaroscopy.

One on the most frequently performed tests is the one using the Doppler effect.

The Doppler test is essential for evaluating the dynamics of the blood flow and detecting pathological reflexes. Moreover, it allows to gather preliminary information concerning anatomical conditions. The examination is most often performed:

- to determine the direction of the blood flow in superficial veins,

- to test the efficiency of the valves in femoral and popliteal veins, great and small saphenous veins, femoral and popliteal veins and crural veins.

Ultrasound examinations using the Doppler effect offer inexpensive and noninvasive phlebologic diagnosis and therefore they are widely used superseding X-ray examinations.

In recent years, apart from the Doppler test commonly used, some other methods are applied that provide hemodynamic information. One of them is plethysmography.

Venous plethysmography enables to determine changes in the blood volume in the lower limbs. The examination is performed under various physiological conditions (with tourniquets, at rest as well as during physical activity) and in different body areas (thigh, shin, foot).

Results - the differences in blood volume may be recorded using the following techniques: strain gauge plethysmography, photoplethysmography (reography in reflected light), air plethysmography, impedance plethysmography, gravimetric etc. However, the above techniques are used very seldom $[15,16,17,18]$.

\section{References:}

1. Wang L, Chu K, Zeng L, Wang L. Primary varicose veins treated with HE's fire needle therapy: a randomized controlled trial Zhongguo Zhen Jiu. 2016; 36:231-236.

2. Andziak P. Chirurgia naczyniowa. In: Medycyna po Dyplomie. 2012; 63-64.

3. Creager MA, Loscalzo J. Choroby naczyń. Lublin: Czelej; 2008.

4. Szmidt J. Podstawy chirurgii. Medycyna Praktyczna. Kraków: 2003.

5. Korzhyk NP. Varicose disease of the lower extremities: causes, complications, choice of methods for treatment and prophylaxis. Klin Khir. 2016; 2:52-55.

6. Smyth RM, Aflaifel N, Bamigboye AA. Interventions for varicose veins and leg oedema in pregnancy. Cochrane Database Syst Rev. 2015; 19: CD001066. doi: 10.1002/14651858.CD001066.pub3.

7. Tisi PV. Varicose veins. BMJ Clin Evid. 2011; 5: pii: 0212.

8. Randall S. Looking after your health. 3. Avoiding varicose veins. Pract Midwife. 2015;18:32-34. 
9. Iannuzzi A, Panico S, Ciardullo AV, Bellati C, Cioffi V, Iannuzzo G, Celentano E, Berrino F, Rubba P. Varicose veins of the lower limbs and venous capacitance in postmenopausal women: relationship with obesity. J Vasc Surg. 2002; 36: 965-968.

10. Noszczyk W. Żylaki i inne choroby żył. Warszawa: PZWL; 2005.

11. Onida S., Davies AH. Varicose veins: diagnosis and management. Nurs Times. 2013; 109: 16-17.

12. Tardaj J. Zastosowanie i przegląd wyrobów uciskowych (kompresjoterapia). Rehabilitacja w praktyce. 2007 ; 4: 18-20.

13. Backup K. Testy kliniczne. Warszawa: PZWL; 2008.

14. Ramelet AA., Monti M. Flebologia Przewodnik. Gdańsk: ViaMedica; 2008.
15. Becker F. Patologia układu żylnego. Gdańsk: ViaMedica; 2006.

16. Fiodorenko - Dumas Ż. Kinezyterapia w praktyce fizjoterapeuty. Wrocław: Górnicki; 2008.

17. Hach W. Chirurgia żył. Tom I. Łódź: Galaktyka; 2009.

18. Piccard JD. Metody obrazowania żył. Gdańsk: MedicalPress; 1999.

\section{Corresponding author adress:}

Prof. A. Pedrycz MD, PhD

Medical University in Lublin, Poland

e-mail: apw4@wp.pl 